\title{
Deep Inhalation Prevents the Respiratory Elastance Response to Methacholine in Rats
}

\author{
CYRIL SCHWEITZER, BRUNO DEMOULIN, GAELLE BELLO, NOELLE BERTIN, ANNE LAURE LEBLANC, AND \\ FRANÇOIS MARCHAL
}

\author{
Laboratoire de Physiologie, Faculté de Médecine, F-54505 Vandoeuvre les Nancy, France
}

\begin{abstract}
The bronchodilator effect of deep inhalation (DI) may be assessed from the time course of respiratory system resistance (Rrs) and reactance (Xrs) measured by the forced oscillation technique at a single frequency. The aim of the study was to assess the effect of DI in the closed chest rat. Under anesthesia and mechanical ventilation, seven Brown Norway rats were given regular DI (BN-di) and six underwent continuous tidal ventilation $(\mathrm{BN})$ throughout an otherwise similar methacholine (Mch) challenge protocol. Rrs and Xrs were monitored at $20 \mathrm{~Hz}$ and apparent respiratory system elastance (Ers) was computed from Xrs. After Mch nebulization, there was a significant increase in Rrs and Ers compared with saline. Ers, but not Rrs, decreased after the DI and BN-di were found to have lower Ers than BN. Thus, DI significantly alters Ers and its response to Mch. Computer simulations suggested reversal of increased viscoelasticity and/or inhomogeneous behavior by the DI in that model. (Pediatr Res 59: 646-649, 2006)
\end{abstract}

$\mathrm{R}^{\mathrm{e}}$ ecent technological progress has promoted a number of methods for the study of respiratory function in subjects that show little cooperation capability. The forced oscillation technique is used in young children to measure the mechanical impedance of the respiratory system ( $\mathrm{Zrs}$ ). An externally generated periodic flow of small amplitude is delivered at the airway opening. Excitation frequencies may range from very low $(<0.5 \mathrm{~Hz})$ to very high $(>50 \mathrm{~Hz})$. In routine pediatric practice, however, the operating range is narrower. The use of very low frequencies is limited by the breathing of the subject and the upper airway wall motion is responsible for significant artefact at higher frequencies $(1,2)$. As a result, most of the relevant information on respiratory mechanical properties in children so far appear to have been obtained somewhere between 5 and $15 \mathrm{~Hz}$ (3). The use of a single excitation frequency allows tracking Zrs changes during breathing (46 ), which is of particular interest in view of the significant time-dependent alteration in airway function that may be observed after a deep inhalation (DI) $(7,8)$. A decrease in airway resistance after a DI is thus highly suggestive of reversal of bronchoconstriction (9-12). Therefore, the airway response to a DI has the capability of assessing the mecha-

Received August 2, 2005; accepted December 14, 2005.

Correspondence: François Marchal, M.D., Laboratoire de Physiologie, Faculté de Médecine, Avenue de la Forêt de Haye, F- 54505 - Vandoeuvre les Nancy, France; e-mail: f.marchal@chu-nancy.fr

Supported by grant EA3450 from "Ministère de l'Education Nationale et de la Recherche."

DOI: 10.1203/01.pdr.0000214892.13788.74 nisms of airway obstruction and has recently been applied to the study of airway hyperresponsiveness in children using the forced oscillation technique $(5,13,14)$.

Whole animal experiments are potentially useful to assess mechanisms through which a DI acts on the airways and to contribute to validating the techniques used in the routine lung function laboratory. Most studies in experimental animals are performed on lung mechanics, i.e. in open-chest condition (12,15-17), which is not representative of the conditions in the pediatric respiratory function laboratory. Airway responsiveness to Mch has been shown in the Brown Norway rat $(18,19)$, and there are few data on how respiratory mechanics may be affected by the occurrence of DI in that model. The aim of the study was therefore to describe the effects of DI in closed chest Brown Norway rats challenged with Mch. The specific end points were (1) the changes in Zrs occurring immediately after the DI and (2) the effects on Zrs of regular administration of DI throughout the experiment. The hypothesis is that DI is associated with bronchodilation and its regular administration decreases airway reactivity.

\section{METHODS}

Group definition. Thirteen Brown Norway rats aged 9 wk were studied. Weight range was 205-265 g. One group (seven rats) received regular DI throughout the experiment (BN-di); the other group (six rats) received no DI throughout an otherwise similar experimental protocol (BN). Animal care and experiments were performed according to the recommendations 86-609 CEE issued by the Council of the European communities and under licenses from the Ministère de l'Agriculture et de la Pêche and the Ministère de l'Enseignement Supérieur et de la Recherche (A54518-03409) and supervision by the Services Véterinaires Départementaux de Meurthe et Moselle.

Anesthesia and surgical preparation. Rats were anesthetized with an intraperitoneal injection of urethane $(1.3 \mathrm{~g} / \mathrm{kg}$, Fluka, Bluchs, Switzerland $)$ and half the loading dose was given about every hour. Animals were placed supine, tracheostomized, and intubated with a tracheal steel cannula (length $26 \mathrm{~mm}$, internal diameter $2 \mathrm{~mm}$, resistance $21.4 \mathrm{hPa} . \mathrm{s} / \mathrm{L}$ and reactance $15.1 \mathrm{hPa} . \mathrm{s} / \mathrm{L}$ at $20 \mathrm{~Hz}$ ). Artificial ventilation was given using a small animal respirator (Harvard, Rodent Ventilator, Model 683) at a frequency of 80 cycle $/ \mathrm{min}$ and a tidal volume of $1 \mathrm{~mL} / 100 \mathrm{~g}$. A positive expiratory pressure was obtained by placing the end of the expiratory line under $2 \mathrm{~cm}$ of water. Rats were paralyzed by an intraperitoneal injection of pancuronium bromide $(0.5 \mathrm{mg} / \mathrm{kg}$, Pavulon, Organon SA, Eragny sur Epte, France). Flow and

Abbreviations: BN, control rats; BN-di, rats receiving deep inhalation; DI, deep inhalation; Ers, respiratory system elastance; Mch, methacholine; P1, before first deep inhalation; P2, after first inhalation; P3, after second deep inhalation; Rrs, respiratory system resistance; Xrs, respiratory system reactance; Zrs, respiratory system impedance 
pressure signals were continuously displayed on the screen of an oscilloscope (Tektronix 2211).

Deep inhalation. DI was obtained by activating a solenoid valve placed on the expiratory line of the respirator to stack several tidal volumes (usually three to five), until the airway pressure displayed on the oscilloscope reached 25-30 $\mathrm{hPa}$. The occlusion was then quickly released and normal tidal ventilation resumed.

Mch challenge. Mch solutions were prepared by diluting Mch (Sigma Chemical Co.-Aldrich, St. Louis, MO) in normal saline to obtain solutions of 5 and $10 \mathrm{mg} / \mathrm{mL}$ (Mch5 and Mch10) that were placed in a DeVilbiss nebulizer connected to a constant air flow generator. The output of the nebulizer saturated with the solution was delivered to a transparent plastic bag connected to the inspiratory line of the respirator for $5 \mathrm{~min}$. A small leak from the plastic bag prevented excessive pressure within the bag. Normal saline $(\mathrm{NaCl})$ was administered in the same conditions. Before any aerosol administration, the pneumotachograph was quickly removed and replaced by a piece of regular tubing to avoid deposition within the flowmeter.

Measuring apparatus. A horn driver-type loudspeaker (ZR4009A, Bouyer, Montauban, France) was placed in parallel with the inspiratory line of the respirator. The impedance of the loudspeaker was high enough not to interfere with the rat's ventilation and to withstand pressures generated during ventilation and DI maneuvers. Airway pressure was measured at a side port proximal to the tracheal cannula with a differential pressure transducer $( \pm 35$ hPa, Micro 176PC14HD2, Honeywell, Scarborough, Ontario, Canada). Flow was measured at the outlet of the cannula with a heated Fleisch \#00 pneumotachograph (Metabo, Hepalinges, Switzerland), connected to a differential pressure transducer similar to the previous one. Both transducers were matched within $1 \%$ of amplitude and 2 degrees of phase up to $30 \mathrm{~Hz}$. The common mode rejection ratio of the flow channel was $60 \mathrm{~dB}$ at $30 \mathrm{~Hz}$. The excitation signal was a sine wave at $20 \mathrm{~Hz}$ generated by a PC type computer equipped with a 12-bit AD/DA conversion board (PC-Lab, Digimétrie, Perpignan, France). The $20-\mathrm{Hz}$ frequency was chosen to adopt a ratio of breathing to excitation frequency roughly similar to what we use in children (14). Pressure and flow signals were low pass-filtered at $32 \mathrm{~Hz}$ using analog filters and digitized at a sampling rate of $160 \mathrm{~Hz}$.

Data processing. The signals were analyzed oscillation cycle per oscillation cycle, providing $20 \mathrm{Zrs}$ measurements per second. The breathing component in the signals was filtered out and the Fourier coefficients of pressure were divided by those of flow to obtain Rrs and Xrs. Finally, the data were corrected for the 2.1-ms time constant of the pneumotachograph and for the impedance of the cannula.

Filtering. To eliminate the flow dependence of Rrs, the final calculation included only those Zrs values lying close to zero flow. It is our experience that the oscillatory flow signal may be subjected to significant distortion, particularly at rapid breathing flow transient. A filtering algorithm was therefore included to quantify the degree of distortion in each oscillation flow cycle and to reject the corresponding data accordingly. Departure of the flow signal from a pure sine wave was computed oscillation per oscillation as the sum of the unsigned differences between the observed flow data and the ideal sine wave having the same Fourier coefficients (20).

Protocol. The study consisted in four epochs (Fig. 1). A baseline recording of respiratory mechanics was started several minutes after body temperature stabilization and recovery from initial procedures. The further three epochs, corresponding respectively to $\mathrm{NaCl}, \mathrm{Mch} 5$, and Mch10, included a 5-min aerosol inhalation and a 5-min $\mathrm{Zrs}$ recording. In $\mathrm{BN}$-di, two DIs were performed, respectively, about 50 and $150 \mathrm{~s}$ from the start of the recording. Tidal breathing was uninterrupted in BN.

Respiratory mechanics. Pilot studies indicated that end-inspiratory data were noisier than end-expiratory data, probably because the change in respiratory flow was more abrupt around zero at end inspiration than at end expiration. Therefore, the expiratory values of Zrs were retained for analysis, and, in what follows, Rrs and Xrs refer to data at end expiration. Rrs and Xrs

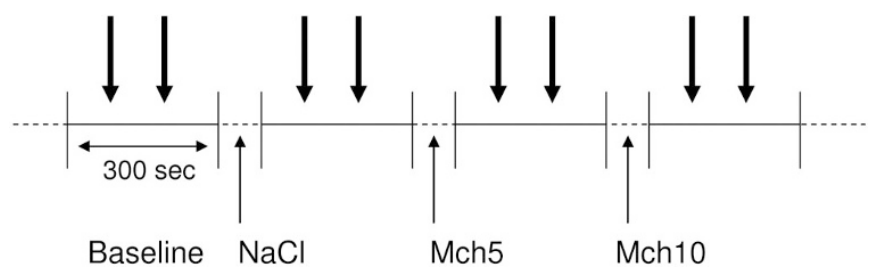

Figure 1. Protocol. Respiratory impedance was measured at baseline, after nebulization of normal saline $(\mathrm{NaCl})$, Mch5 and $10 \mathrm{mg} / \mathrm{mL}$ (Mch5, Mch10). Large arrows indicate where DIs were performed. One recording epoch lasted $300 \mathrm{~s}$.

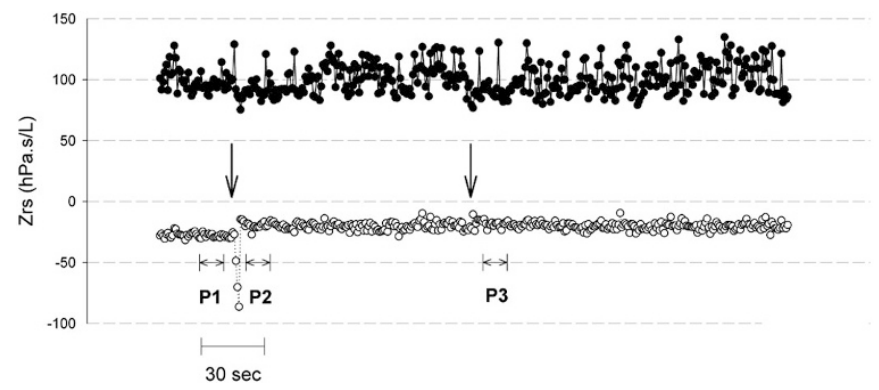

Figure 2. Effects of DI (arrows) after Mch inhalation $(5 \mathrm{mg} / \mathrm{mL})$ on breathby-breath end-expiratory Rrs $(-)$ and Xrs $(\bigcirc)$. Rrs and Xrs were averaged over about 10 breaths before the first DI (P1) and after the first and second DIs (P2, P3).

were computed on three parts of each recording (P1, P2, and P3), each part including at least 10 breathing cycles over which the data were averaged (Fig. 2). P1 was the initial part of the recording; P2 and P3 followed, respectively, the first and second DIs in $\mathrm{BN}$-di and corresponded to those timings in BN. For easier understanding of the data, Xrs was expressed as apparent respiratory system elastance (Ers), by multiplying - Xrs by angular frequency $(2 . \pi . f$, where $f=20 \mathrm{~Hz})$.

Response to Mch challenge. Rrs and Ers values read from P1 were compared among saline, Mch5 and Mch10, and between BN-di and BN.

Effects of DI. The Rrs or Ers ratio of P2 to P1 $\left(\operatorname{Rrs}_{2 / 1}\right.$ and $\left.\operatorname{Ers}_{2 / 1}\right), \mathrm{P} 3$ to P1 $\left(\operatorname{Rrs}_{3 / 1}, E s_{3 / 1}\right)$ were calculated to assess, respectively, the effects of one and two DIs.

Statistics. Statistical analysis was performed using the Statview software (Abacus Concepts Inc., Berkeley, CA). Effects of Mch, DI, and group comparisons were assessed using an analysis of variance with repeated measurements. When a significant effect was found, a $t$ test was used to locate the difference. Statistical significance was retained at $p<0.05$. Data are expressed as mean $\pm \mathrm{SEM}$.

\section{RESULTS}

Baseline Zrs (i.e. read from P1) was similar in the two groups. Rrs was $57.1 \pm 3.0$ and $59.4 \pm 4.6 \mathrm{hPa} . \mathrm{s} / \mathrm{L}$, respectively, in BN and BN-di, while Ers was, respectively, $3636 \pm$ 538 and $3178 \pm 239 \mathrm{hPa} / \mathrm{L}$.

Effects of DI. A typical recording of the effect of DI on Rrs and Xrs is presented in Figure 2. It may be seen that after the first DI, Xrs becomes less negative with little change in Rrs. The second DI has no measurable effect. Overall, $\operatorname{Rrs}_{2 / 1}$ (Fig. 3A) and $\mathrm{Rrs}_{3 / 1}$ (not shown) are not different between BN and $\mathrm{BN}$-di, indicating no significant effect of DI on Rrs. In contrast, $\mathrm{Ers}_{2 / 1}$ is significantly lower in BN-di than in BN after $\mathrm{NaCl}$, Mch5, and Mch10 ( $p<0.001$, Fig. 3B), indicating a significant decrease in Ers by DI. Ers ${ }_{3 / 1}$ is still different between the two groups ( $p=0.002$, not shown).

Response to Mch challenge. The analysis of variance indicated that Rrs was significantly larger after Mch5 and Mch10 compared with $\mathrm{NaCl}(p=0.01$, Fig. $4 A$ ), was not different between $\mathrm{BN}$ and $\mathrm{BN}-\mathrm{di}$, and there was no significant interaction between DI and Mch. Ers was significantly larger after Mch5 and Mch10 compared with after $\mathrm{NaCl}(p<$ $0.0001)$, and in contrast to Rrs, Ers was also significantly larger in $\mathrm{BN}$ than in BN-di $(p=0.0007$ Fig. $4 B)$. There also was a significant interaction between Mch and DI, indicating that the effect of DI depended on the Mch dose $(p=0.0008)$.

\section{DISCUSSION}

The important finding in this study is that a DI appeared to acutely decrease Ers in Brown Norway rats and the regular 

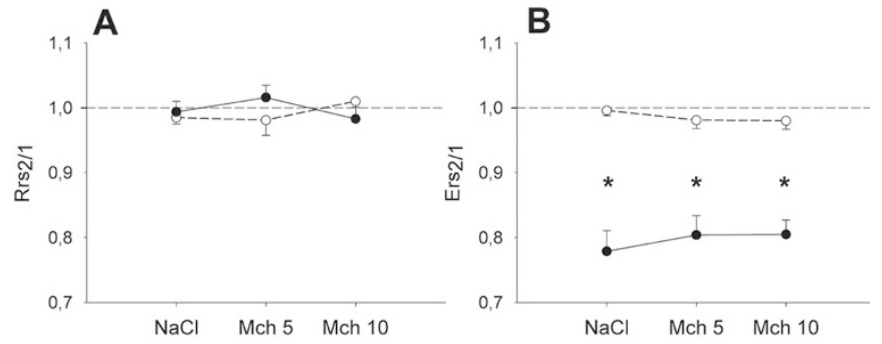

Figure 3. $\operatorname{Rrs}_{2 / 1}$ and $\mathrm{Ers}_{2 / 1}$, the ratios of, respectively, respiratory resistance and elastance of P2 to P1, as defined in Figure 2, express the effects of DI (see "Methods"). NaCl, Mch5, and Mch10: after nebulization of saline and Mch 5 and $10 \mathrm{mg} / \mathrm{mL}$. (A) $\operatorname{Rrs}_{2 / 1}$ is close to 1 and similar in $\mathrm{BN}(, n=6)$ and $\mathrm{BN}-\mathrm{di}$ $(\bigcirc, n=7)$, indicating lack of change in Rrs after DI. (B) In contrast, Ers ${ }_{2 / 1}$ is around 0.80 in BN-di and thus significantly lower than $\mathrm{BN}\left({ }^{*} p<0.001\right)$, indicating significant decrease in Ers by DI.
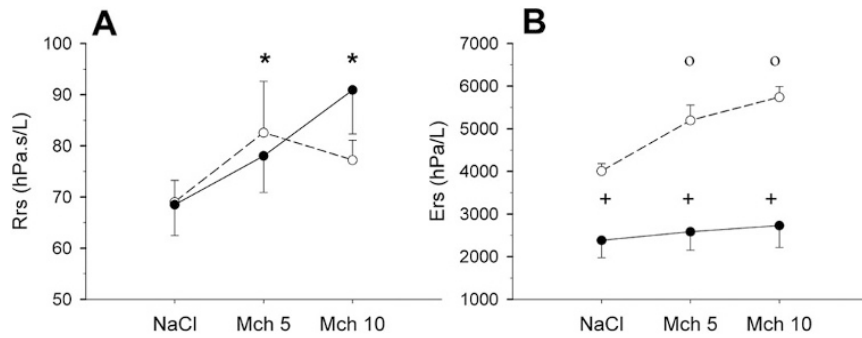

Figure 4. Same conditions and symbols as in Figure 3. (A) Rrs is significantly increased from $\mathrm{NaCl}$ after Mch5 and $\mathrm{Mch} 10\left({ }^{*} p=0.01\right)$, and there is no significant difference between $\mathrm{BN}(\boldsymbol{\bullet}, n=6)$ and $\mathrm{BN}$-di $(\bigcirc, n=7)$. (B) Ers is significantly increased after Mch5 and Mch10 compared with after $\mathrm{NaCl}$ in $\mathrm{BN}(\mathrm{O}, p<0.0001)$ and is also lower in $\mathrm{BN}$-di compared with $\mathrm{BN}$ $(+p=0.0007)$.

administration of DI throughout the experiment significantly minimized the Ers response to Mch, with little impact on Rrs. To the best of our knowledge, this is the first report on tracking Zrs changes induced by DI and concurrently assessing the effects of repeated DIs after Mch inhalation in closed chest Brown Norway rats. The analysis was performed without interfering with volume history or ventilation, retaining only those Zrs values close to zero flow to eliminate the influence of flow dependence of Rrs and applying a new filtering algorithm to exclude corrupted data oscillation per oscillation (20). We chose to express the Xrs data as apparent respiratory elastance, as previously suggested (21) because the term is much more familiar and allows straightforward understanding of the reported changes. This implies that most of Xrs is determined by elastic and viscoelastic properties of the respiratory system, while from a theoretical point of view, the airway inertance could also be involved. However, airway inertance has been shown to be negligible in rodents (22) and to undergo only minimal changes after Mch $(17,23,24)$. Airway inertance ought to change in the same direction as airway resistance, which is close to Rrs above a few $\mathrm{Hz}$ (see below). The latter did not change significantly after the DI so that airway inertance was unlikely to contribute significantly to the change illustrated in Figure 3.

One important end point in this study was to characterize respiratory mechanics using the very same tool as in asthmatic children where the use of a single oscillation frequency is favored in our setup for the following reasons: (1) the signal- to-noise ratio is optimal, (2) it provides an easy description for the time course of Zrs change after a DI, (3) studying the response of the chest from 0.5 to $10-20 \mathrm{~Hz}$, as done in experimental animals $(17,23,25)$ is hampered by the spontaneous breathing of the child, and (4) our prior experience with model estimation of respiratory mechanical parameters from multiple frequency data has shown significant limitation in children with airway obstruction (26). On the other hand, a single frequency does not allow estimation of airway and tissue mechanics as previously described (25), and it may be questioned how much these measurements of $\mathrm{Zrs}$ are representative of the changes occurring in the airways and/or lung. Comparing measurements in rats with closed versus open chests indicates similar identification of parenchymal and airway responses to Mch by both approaches, with smaller sample size being necessary to show group differences in the former condition (23). Those findings are supported by comparative assessment of lung and respiratory mechanics in the rat that yields similar values of lung and respiratory resistance (27), indicating low chest wall resistance. On the other hand, significantly different values of tissue damping and elastance are estimated from respiratory and lung mechanics data $(23,27)$. However, the chest wall is unlikely to account for the observed changes in Ers during an experiment where the animal is paralyzed.

Although it may differ from airway resistance during a total lung capacity maneuver $(28,29)$, Rrs above a few $\mathrm{Hz}$ and at functional residual capacity may be taken as representative of conducting airways $(21,30)$. The observation that the beneficial effect of DI was not expressed on Rrs in the current preparation therefore suggests little impact of DI on conducting airway smooth muscle tone. Positive expiratory pressure was maintained throughout the experiment so that a major change in lung volume was unlikely to account for the change in Xrs. This was supported by the fact that the tidal volume trace did not show evidence of a change in end-expiratory level immediately after DI. The Xrs decrease during expiration has been reported as an indicator of expiratory flow limitation in humans (31). However, our observations in the rat were made in such conditions that expiratory flow limitation was unlikely to account for the findings on Xrs as described in a previous animal experiment (32). In rabbits, Xrs was found to decrease markedly early in expiration but neared the inspiratory value at the end of expiration, close to zero flow, the timing chosen in our study to measure Xrs. In addition, the induction of expiratory flow limitation in that preparation was constantly associated with negative expiratory pressure, while our animals, again, were ventilated with a positive expiratory pressure (32).

Altogether, there appear to be three plausible explanations to the observed reversal by DI of Ers, but not Rrs, response to Mch: a true decrease in tissue elastance and damping together with reversal of small airway closure, a decreased central airway shunting as due to decreased peripheral airway resistance, and a decreased regional inhomogeneity of mechanical time constants. The lung impedance response to Mch was studied between 0.5 and $19.75 \mathrm{~Hz}$ in vagotomized open chest rats exposed to various DI protocols given before Mch inha- 
lation (17) and the data analyzed with the constant phase model (25). The preventive effects of DI on Mch-induced alterations were clearly demonstrated on lung tissue damping and elastance, with little effect on airway resistance (17). In the normal lung, elastance and tissue damping effectively express elastic and viscoelastic properties of the tissue. However, after Mch inhalation, the induced airways inhomogeneity has been suggested to contribute to change these parameters $(17,24,33)$. The effect of inhomogeneity was simulated using a computer model featuring the central airways and two parallel peripheral airways compartments, each in series with a tissue compartment. The DI was assumed to reduce the inhomogeneous distribution of either the resistance between the peripheral airways or the viscoelasticity between the tissue compartments. It was thus found that equalization of peripheral airway resistances had very little influence on Ers. By contrast, homogenization of tissue damping could readily account for the decrease in Ers reported in our experimental animals. Because the excitation frequency in our study was comparatively high, it is speculated that the observed increase in apparent (dynamic) elastance after DI is more likely to reflect an improvement in inhomogeneous distribution of tissue time constants rather than a uniform increase in lung elastance and damping.

Thus, these experiments indicate the protective effect of DI against Mch-induced airway obstruction, decreasing tissue viscoelasticity and/or its inhomogeneous distribution within the lung, with little apparent effect on the central airways. The finding of a lack of effect of DI on the central airways is also consistent with previous studies in rats (17) and dogs (34). The impact of DI on Zrs gives support to the validity of Xrs in the detection of a positive response to Mch previously suggested in children (35). On the other hand, the lack of change in Rrs after the DI contrasts with prior observations in children $(13,14,36)$. Generally, the data also point to the important impact of DI and hence of the breathing pattern and volume history on airway reactivity.

Acknowledgments. The authors thank Dr. R. Peslin for the measuring software, computer simulation, and fruitful discussion; C. Duvivier and G. Colin for valuable technical assistance; and E. Gerhardt for secretarial help.

\section{REFERENCES}

1. Cauberghs M, Van de Woestijne KP 1989 Effect of upper airway shunt and series properties on respiratory impedance measurements. J Appl Physiol 66:2274-2279

2. Marchal F, Haouzi P, Peslin R, Duvivier C, Gallina C 1992 Mechanical properties of the upper airway wall in children and their influence on respiratory impedance measurements. Pediatr Pulmonol 13:28-33

3. Oostveen E, MacLeod D, Lorino H, Farre R, Hantos Z, Desager K, Marchal F 2003 ERS Task Force on Respiratory Impedance Measurements. The forced oscillation technique in clinical practice: methodology, recommendations and future developments. Eur Respir J 22:1026-1041

4. Lutchen KR, Jensen A, Atileh H, Kaczka DW, Israel E, Suki B, Ingenito EP 2001 Airway constriction pattern is a central component of asthma severity: the role of deep inspirations. Am J Respir Crit Care Med 164:207-215

5. Marchal F, Schweitzer C, Moreau-Colson C 2002 Respiratory impedance response to a deep inhalation in children with history of cough or asthma. Pediatr Pulmonol $33: 411-418$
6. Thorpe CW, Salome CM, Berend N, King GG 2004 Modeling airway resistance dynamics after tidal and deep inspirations. J Appl Physiol 97:1643-1653

7. Wang L, Pare PD 2003 Deep inspiration and airway smooth muscle adaptation to length change. Respir Physiol Neurobiol 137:169-178

8. Fredberg JJ, Jones KA, Nathan M, Raboudi S, Prakash YS, Shore SA, Butler JP, Sieck GC 1996 Friction in airway smooth muscle: mechanism, latch, and implications in asthma. J Appl Physiol 81:2703-2712

9. Fish JE, Ankin MG, Kelly JF, Peterman VI 1981 Regulation of bronchomotor tone by lung inflation in asthmatic and nonasthmatic subjects. J Appl Physiol 50:10791086

10. Skloot G, Permutt S, Togias A 1995 Airway hyperresponsiveness in asthma: a problem of limited smooth muscle relaxation with inspiration. J Clin Invest 96:2393-2403

11. Fredberg JJ, Inouye D, Miller B, Nathan M, Jafari S, Raboudi SH, Butler JP, Shore SA 1997 Airway smooth muscle, tidal stretches, and dynamically determined contractile states. Am J Respir Crit Care Med 156:1752-1759

12. Brown RH, Mitzner W 2001 Airway response to deep inspiration: role of inflation pressure. J Appl Physiol 91:2574-2578

13. Milanese M, Mondino C, Tosca M, Canonica GW, Brusasco V 2000 Modulation of airway caliber by deep inhalation in children. J Appl Physiol 88:1259-1264

14. Schweitzer C, Moreau-Colson C, Marchal F 2002 Respiratory impedance response to a deep inhalation in asthmatic children with spontaneous airway obstruction. Eur Respir J 19:1020-1025

15. Gunst SJ, Warner DO, Wilson TA, Hyatt RE 1988 Parenchymal interdependence and airway response to methacholine in excised dog lobes. J Appl Physiol 65:24902497

16. Bates JH, Lauzon AM, Dechman GS, Maksym GN, Schuessler TF 1994 Temporal dynamics of pulmonary response to intravenous histamine in dogs: effects of dose and lung volume. J Appl Physiol 76:616-626

17. Hirai T, Bates JH 2001 Effects of deep inspiration on bronchoconstriction in the rat Respir Physiol 127:201-215

18. Bellofiore S, Martin JG 1988 Antigen challenge of sensitized rats increases airway responsiveness to methacholine. J Appl Physiol 65:1642-1646

19. Eidelman DH, DiMaria GU, Bellofiore S, Wang NS, Guttmann RD, Martin JG 1991 Strain-related differences in airway smooth muscle and airway responsiveness in the rat. Am Rev Respir Dis 144:792-796

20. Marchal F, Schweitzer C, Choné C, Demoulin B, Peslin R 2004 Filtering artefacts in measurements of forced oscillation respiratory impedance in young children. Physiol Meas 25:1155-1166

21. Kaczka DW, Ingenito EP, Israel E, Lutchen KR 1999 Airway and lung tissue mechanics in asthma. Effects of albuterol. Am J Respir Crit Care Med 159:169-178

22. Gomes RF, Shen X, Ramchandani R, Tepper RS, Bates JH 2000 Comparative respiratory system mechanics in rodents. J Appl Physiol 89:908-916

23. Petak F, Hall GL, Sly PD 1998 Repeated measurements of airway and parenchymal mechanics in rats by using low-frequency oscillations. J Appl Physiol 84:1680-1686

24. Petak F, Hantos Z, Adamicza A, Asztalos T, Sly PD 1997 Methacholine-induced bronchoconstriction in rats: effects of intravenous vs. aerosol delivery. J Appl Physiol 82:1479-1487

25. Hantos Z, Daroczy B, Suki B, Nagy S, Fredberg JJ 1992 Input impedance and peripheral inhomogeneity of dog lungs. J Appl Physiol 72:168-178

26. Marchal F, Bouaziz N, Baeyert C, Gallina C, Duvivier C, Peslin R 1996 Separation of airway and tissue properties by transfer respiratory impedance and thoracic gas volume in reversible airway obstruction. Eur Respir J 9:253-261

27. Hirai T, McKeown KA, Gomes RF, Bates JH 1999 Effects of lung volume on lung and chest wall mechanics in rats. J Appl Physiol 86:16-21

28. Black LD, Dellaca R, Jung K, Atileh H, Israel E, Ingenito EP, Lutchen KR 2003 Tracking variations in airway caliber by using total respiratory vs. airway resistance in healthy and asthmatic subjects. J Appl Physiol 95:511-518

29. Hantos Z, Collins RA, Turner DJ, Janosi TZ, Sly PD 2003 Tracking of airway and tissue mechanics during TLC maneuvers in mice. J Appl Physiol 95:1695-1705

30. Hantos Z, Adamicza A, Govaerts E, Daroczy B 1992 Mechanical impedances of lungs and chest wall in the cat. J Appl Physiol 73:427-433

31. Dellaca RL, Santus P, Aliverti A, Stevenson N, Centanni S, Macklem PT, Pedotti A, Calverley PM 2004 Detection of expiratory flow limitation in COPD using the forced oscillation technique. Eur Respir J 23:232-240

32. Vassiliou M, Peslin R, Saunier C, Duvivier C 1996 Expiratory flow limitation during mechanical ventilation detected by the forced oscillation method. Eur Respir J 9:779-786

33. Lutchen KR, Hantos Z, Petak F, Adamicza A, Suki B 1996 Airway inhomogeneities contribute to apparent lung tissue mechanics during constriction. J Appl Physiol 80:1841-1849

34. Ludwig MS, Dreshaj I, Solway J, Munoz A, Ingram RH Jr 1987 Partitioning of pulmonary resistance during constriction in the dog: effects of volume history. $\mathrm{J}$ Appl Physiol 62:807-815

35. Bouaziz N, Beyaert C, Gauthier R, Monin P, Peslin R, Marchal F 1996 Respiratory system reactance as an indicator of the intrathoracic airway response to methacholine in children. Pediatr Pulmonol 22:7-13

36. Marchal F, Schweitzer C, Khallouf S 2003 Respiratory conductance response to deep inhalation in children with exercise-induced bronchoconstriction. Respir Med 97:921-927 